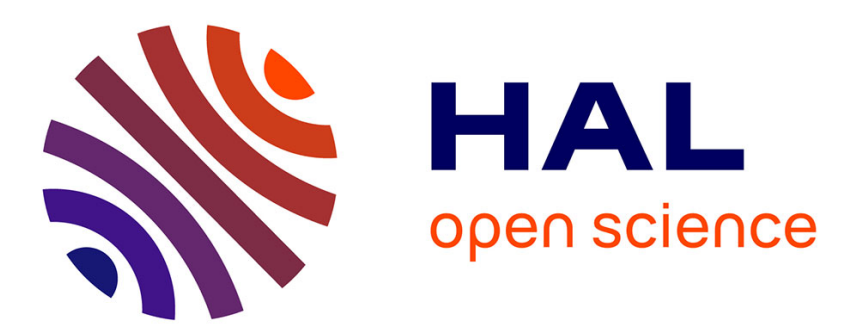

\title{
Lab-on-a-chip device for fabrication of therapeutic microbubbles on demand
}

Spiros Kotopoulis, Sabrina Eder, Martin Greve, Bodil Holst, Michiel Postema

\section{To cite this version:}

Spiros Kotopoulis, Sabrina Eder, Martin Greve, Bodil Holst, Michiel Postema. Lab-on-a-chip device for fabrication of therapeutic microbubbles on demand. Biomedical Engineering $=$ Biomedizinische Technik, 2013, 58 (Suppl. 1), pp.4037. 10.1515/bmt-2013-4037 . hal-03193185

\section{HAL Id: hal-03193185 \\ https://hal.science/hal-03193185}

Submitted on 11 Apr 2021

HAL is a multi-disciplinary open access archive for the deposit and dissemination of scientific research documents, whether they are published or not. The documents may come from teaching and research institutions in France or abroad, or from public or private research centers.
L'archive ouverte pluridisciplinaire HAL, est destinée au dépôt et à la diffusion de documents scientifiques de niveau recherche, publiés ou non, émanant des établissements d'enseignement et de recherche français ou étrangers, des laboratoires publics ou privés. 


\title{
Lab-on-a-chip device for fabrication of therapeutic microbubbles on demand
}

\author{
Spiros Kotopoulis ${ }^{1,2}$, Sabrina D Eder ${ }^{2}$, Martin M Greve ${ }^{2}$, Bodil Holst ${ }^{2}$, Michiel Postema ${ }^{2}$ \\ ${ }^{1}$ National Centre for Ultrasound in Gastroenterology, Haukeland University Hospital, Bergen, Norway \\ ${ }^{2}$ Department of Physics and Technology, University of Bergen, Bergen, Norway
}

Spiros.Kotopoulis@uib.no

\begin{abstract}
Electron beam lithography (EBL) was used to fabricate microchannels to produce microbubbles with highly homogeneous size distributions. Using the EBL technique, microchannels can be prototyped at a fast and cost effective rate allowing for evaluation of various microbubble shell materials.
\end{abstract}

Keywords: Microbubbles, EBL, Targeted drug delivery.

\section{Introduction}

Sonoporation is an up-and-coming technique used to enhance localised drug delivery [1-3]. Sonoporation can be defined as the mechanism that forms microscopic pores in cell membranes with the use of ultrasound, or ultrasound and microbubbles [4,5]. Given that only a defined size of microbubbles are effective for sonoporation [5]. The vast distribution of commercial microbubbles limits the efficacy of sonoporation. Table 1 shows the size distribution of several commercial microbubbles.

Mircrofluidics are used for the fabrication of droplets for drug and chemicals [6], but the resultant droplets are extremely large and not acoustically active. This is primarily due to the limitations of fabrication using photolithography where channels are limited to widths of around $1 \mu \mathrm{m}$.

To narrow the vast size distribution of the microbubbles, we are investigating the use of electron-beam lithography (EBL) to fabricate micron-sized microfluidic chambers allowing for the formation of micron sized microbubbles encapsulating drugs.

Table 1: Size distribution and gas content of some commercial ultrasound contrast agents (microbubbles) [7].

\begin{tabular}{|c|c|c|c|}
\hline Contrast agent & $\begin{array}{l}\text { Mean } \\
\text { diameter } \\
(\mu \mathrm{m})\end{array}$ & $\begin{array}{l}\text { Size }<10 \mu \mathrm{m} \\
\%\end{array}$ & Gas \\
\hline BR14 & 3.0 & 95 & $\mathrm{C}_{4} \mathrm{~F}_{10}$ \\
\hline Definity ${ }^{\circledR}$ & $1.1-3.3$ & 98 & $\mathrm{C}_{3} \mathrm{~F}_{8}$ \\
\hline 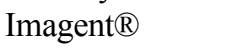 & 6.0 & 99.8 & $\mathrm{C}_{6} \mathrm{~F}_{14} / \mathrm{N}_{2}$ \\
\hline Optison $^{\mathrm{TM}}$ & $2.0-4.5$ & 93 & $\mathrm{C}_{3} \mathrm{~F}_{8}$ \\
\hline Quantison $^{\mathrm{TM}}$ & 3.2 & $?$ & Air \\
\hline SonoVue $\mathbb{}$ & 2.5 & 99 & $\mathrm{SF}_{6}$ \\
\hline AI-700 & 2 & 99 & $\mathrm{C}_{4} \mathrm{~F}_{10}$ \\
\hline CARDIOsphere $\AA$ & 4.0 & $?$ & $\mathrm{~N}_{2}$ \\
\hline EchoGen $®$ & $2-5$ & 99 & $\mathrm{C}_{5} \mathrm{~F}_{12}$ \\
\hline MicroMarker ${ }^{\mathrm{TM}}$ & 2.5 & 99.9 & $\mathrm{C}_{4} \mathrm{~F}_{10} / \mathrm{N}_{2}$ \\
\hline
\end{tabular}

\begin{tabular}{llll}
\hline Contrast agent & $\begin{array}{l}\text { Mean } \\
\text { diameter } \\
(\boldsymbol{\mu m})\end{array}$ & $\begin{array}{l}\text { Size }<\mathbf{1 0} \boldsymbol{\mu m} \\
\mathbf{\%}\end{array}$ & Gas \\
\hline Sonazoid & $2.4-3.6$ & $?$ & $\mathrm{C}_{4} \mathrm{~F}_{10}$ \\
\hline
\end{tabular}

\section{Methods}

A fused quartz substrate (H.Baumbach \& Co. LTD, Suffolk, United Kingdom) was used as the base material for the microchannels. Using quartz allows for maximum optical clarity and for future evaluation of microbubbles when fluorescence is used, e.g., when embedding a chemotherapeutic into the shell or core of the bubble. A 50-nm chrome layer was deposited using an electron beam evaporator (FC-2000, Temescal, Livermore, CA, USA) to act as the etch mask for the subsequent reactive ion etch. A 160-nm AR-P 672.08 PMMA (ALLRESIST GmBH, Strausberg, Germany) layer was spin coated on top of the chrome layer to structure the chrome mask.

The substrate was then placed inside the EBL (e_Line, Raith GmbH, Dortmund, Germany), the desired pattern was drawn in the corresponding software and subsequently written into the PMMA layer.

As a next pattern transfer step, the structure in the exposed PMMA layer was developed and a wet etch process was performed to remove the chrome in the exposed areas, leaving the chrome mask for the final step. The final step was to perform reactive ion etching using $\mathrm{CF}_{4}$ gas. This process etches the microchannels into the quartz substrate, i.e., creating the channel depths. In this instance the sample was etched for $10 \mathrm{~min}$.

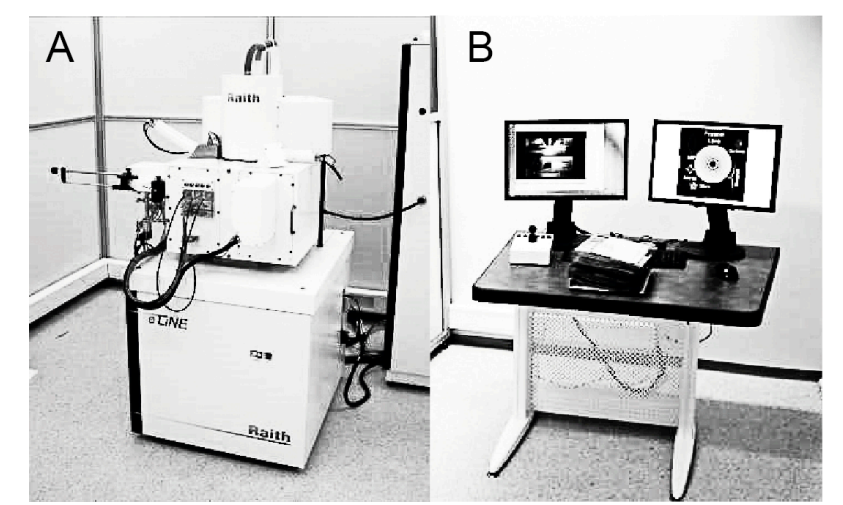

Figure 1: Electron-beam lithography system used to fabricate microfluidics channels with nanometre resolution. 
To connect the capillaries to feed the gas and lipids for the shell material, a mould with the locators for the inlet and outlets was printed using a 3D printer (Projet 1500, 3D Systems, Rock Hill, SC, USA) and filled with a elastomer (SLYGARD 184, Dow Corning, Midland, MI, USA). This was attached to the quartz substrate after plasma cleaning forming a permanent bond.

\section{Results}

The e-Line system performed fast and accurate patterning in a quick time $<1$ hour. Figure 2 shows the results prior to etching. Fig. 2A shows the size of the inputs for the gas and shell materials of the bubbles, whilst Fig. 2B shows the constriction zone of $2.5 \mu \mathrm{m}$ width and final channel path of $10 \mu \mathrm{m}$ width.

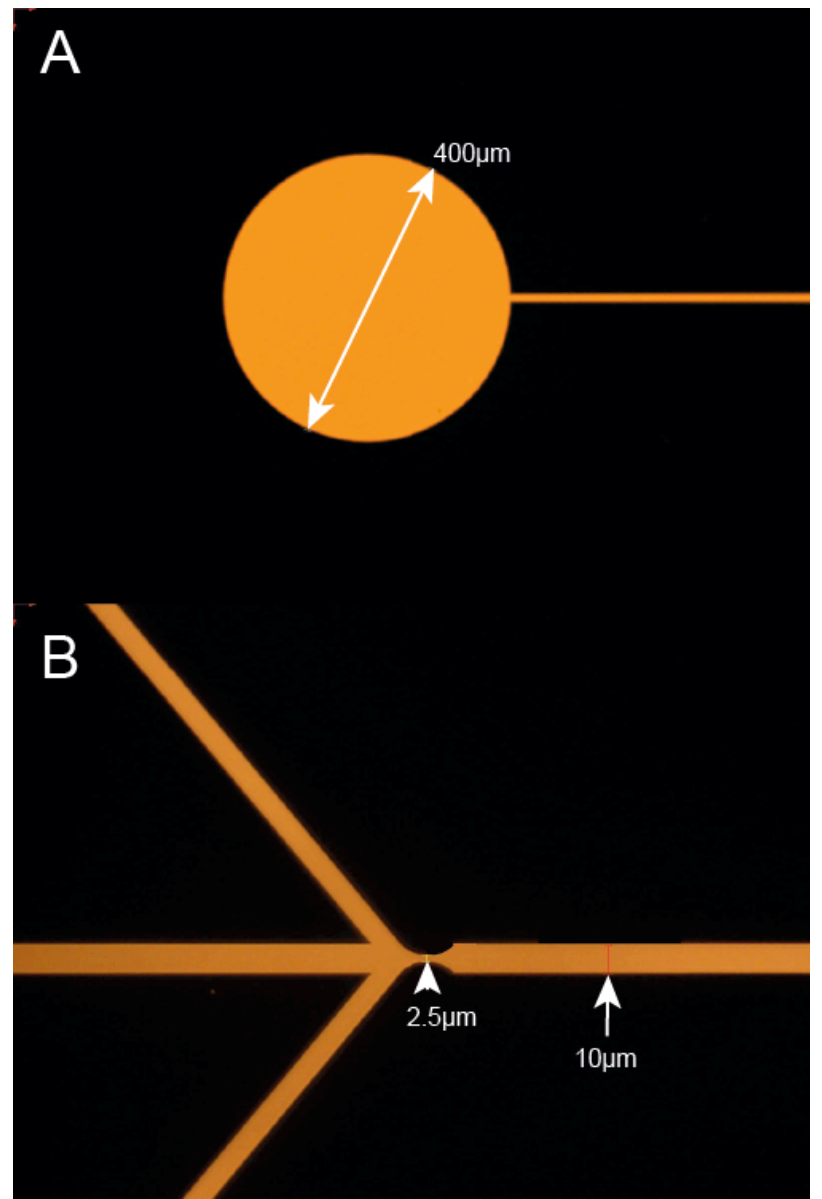

Figure 2: Result of e-beam lithography for a prototype microfluidic design. Image captured using optical microscopy. Panel A shows a disc that will be used as the input channel for the shell material or gas. Panel B shows a $2.5 \mu \mathrm{m}$ constriction in the region where the gas and lipid components meet.

Figure 3 shows the effect of plasma etching on the quartz substrate. After 10 min etching, a depth of $650 \mathrm{~nm}$ was measured. This showed that it was possible to control the channel depth with high fidelity at a rate of approximately $7 \times 10^{1} \mathrm{~nm} / \mathrm{min}$.

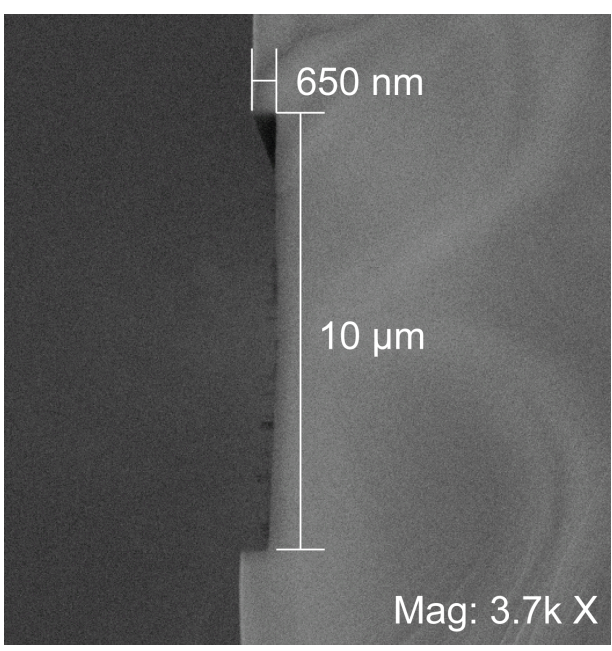

Figure 3: Result of plasma etching using $\mathrm{CF}_{4}$ gas for a total duration of $10 \mathrm{~min}$. Image captured electron microscopy (e_Line). A channel depth of $650 \mathrm{~nm}$ was measured.

\section{Discussion}

Using EBL for the fabrication of microchannels for microbubbles is a fast and cost effective technique that allows high spatial resolution. EBL provides several benefits over traditional lithography methods as it allows structures ranging in size from several nanometres to even several millimetres in a single operation. It ensures high repeatability and several prototypes can be manufactured at the same time with negligible increase in time. Furthermore it allows for fabrication of custom microbubbles on demand.

\section{Acknowledgement}

We would like to thank UiB Nanostructures Laboratory, Department of Physics and Technology at the University of Bergen.

\section{Bibliography}

[1] J. Wu, et al., "Sonoporation, anti-cancer drug and antibody delivery using ultrasound," Ultrasonics, vol. 44, pp. E21-E25, Dec 222006.

[2] Y. Qiu, et al., "Microbubble-induced sonoporation involved in ultrasound-mediated DNA transfection in vitro at low acoustic pressures," Journal of Biomechanics, vol. 45, pp. 1339-45, May 112012.

[3] M. Postema, et al., "Sonoporation: Why microbubbles create pores," Ultraschall in Med., vol. 33, pp. 97-98, 2012.

[4] M. Postema, et al., "Ultrasound-guided delivery and sonoporation," in Ultrasound in Gastroenterology. 10years aniversary of National Center for Ultrasound in Gastroenterology, 2011, pp. 57-59.

[5] A. Delalande, et al., "Sonoporation at a low mechanical index," Bub. Sci. Eng. Tech., vol. 3, pp. 3-11, 2011.

[6] P. S. Dittrich and A. Manz, "Lab-on-a-chip: microfluidics in drug discovery," Nat Rev Drug Discov, vol. 5, pp. 2108, Mar 2006.

[7] M. Postema, Fundamentals of medical ultrasonics. Milton Park, Abingdon, Oxon ; New York: Spon Press, 2011. 